\title{
Relevance of in vitro agar based screens to characterize the anti-fungal activities of bacterial endophyte communities
}

\author{
Hanan R. Shehata ${ }^{1,2}$, Eric M. Lyons², Katerina S. Jordan ${ }^{1}$ and Manish N. Raizada ${ }^{1 *}$
}

\begin{abstract}
Background: Endophytes are microbes that inhabit internal plant tissues without causing disease. Plant microbial communities consist of large numbers of endophyte species. Understanding the functions of these endophytes is a major challenge. An important function of some endophytes is to suppress fungal pathogens. Typically, plant associated microbes are screened for anti-fungal activities in vitro using the high-throughput dual culture screen, but it is not clear whether this method correlates with the activities of these microbes in planta. Furthermore, it is not clear whether in vitro screening captures all of the microbes that show this activity inside plants. The objective of this study was to evaluate the relevance of the in vitro dual culture method for screening endophytes with anti-fungal activity.

Results: In parallel, 190 bacterial endophytes from the corn grass family (Zea) were screened for suppression of two fungal pathogens (Sclerotinia homoeocarpa and Rhizoctonia solani) using the in vitro dual culture method, and in planta using the model plant, creeping bentgrass. All endophytes that showed anti-fungal activity in planta against Sclerotinia homoeocarpa and Rhizoctonia solani (3 or 4 strains, respectively, out of 190), were captured in vitro. The in vitro and in planta screening results strongly correlated ( $r=0.81$ and $r=0.94$ for the two pathogens, respectively).

Conclusions: Evidence was gained here that the in vitro dual culture method is a relevant method for high throughput screening of plant endophyte communities for anti-fungal activity. In our study, the method captured all of the microbes that suppressed the corresponding pathogens in planta.
\end{abstract}

Keywords: Endophyte, Plant, Zea, Biological control, Dual culture, in planta, Creeping bentgrass, Sclerotinia homoeocarpa, Rhizoctonia solani

\section{Background}

Plant microbiome communities consist of large numbers of species (endophytes) that can affect plant health, nutrition, growth and tolerance to abiotic and biotic stresses $[1,2]$. A major function of plant associated microbes is to control plant pathogens, especially fungi [3]. This is usually mediated by direct antagonism through production of antimicrobials, competition for nutrients or space, or induction of host plant defenses [2]. Due to the complexity of plant microbiomes, a rapid method is necessary to screen for their beneficial activities to plants [3]. Obviously, screening hundreds of these microbes in

\footnotetext{
*Correspondence: raizada@uoguelph.ca

${ }^{1}$ Department of Plant Agriculture, University of Guelph, Guelph, ON N1G 2W1, Canada

Full list of author information is available at the end of the article
}

whole plants is challenging $[1,4]$. Researchers typically test for anti-fungal activities in vitro first, then carry forward only the positive candidates to plant-based assays, excluding the bulk of the microbes that showed no antipathogen activity [4-8]. Dual culture screens are widely used as they are high-throughput, but it is not clear if the results correlate with microbial activities in planta (i.e. whether microbes with in planta anti-fungal activities are missed). We could find few systematic comparisons of in vitro dual culture versus in planta screens for endophytes that suppress plant disease [9].

The objective of this study was to evaluate the relevance of the in vitro dual culture method as a systematic and comprehensive method for screening endophytes for anti-fungal activity. Here we screened 190 bacterial endophytes against fungal pathogens using in planta 
screens first then conducted in vitro dual culture screens. The endophytes were previously isolated from the seeds, shoots and roots of 14 genotypes of the corn family (genus Zea) [10, 11]. As Zea plants are large, we used a smaller genetic grass relative for in planta screens, namely creeping bentgrass (Agrostis stolonifera L.), as plants could grow and develop disease symptoms in tubes efficiently. Creeping bentgrass is one of the most widely used turfgrasses on golf courses [12]. Endophytes were screened for in planta suppression of two fungal pathogens, Sclerotinia homoeocarpa (dollar spot disease) [13] and Rhizoctonia solani (brown patch disease) [14]. Sclerotinia homoeocarpa is the most economically important disease that affects creeping bentgrass $[13,15]$ and is also widespread within the grass family [16]. Rhizoctonia solani is another major fungal pathogen that affects turfgrass species including creeping bentgrass [17]. R. solani affects diverse crops including potato, tomato, cucumber, green pea and rice [18-23].

\section{Results}

Screening for inhibition of S. homoeocarpa

In planta visual screening of 190 Zea endophytes for antifungal activity revealed that three endophytes (3A12, 3C11, 5C9) controlled $S$. homoeocarpa in creeping bentgrass in all $3 / 3$ tubes tested $(\mathrm{n}=\sim 30$ plants/tube) (Fig. 1a-e; Additional file 1: Table S3 and Additional file 2: Table S4). The antifungal strains were previously identified based on their 16S rRNA sequences (Additional file 3: Table $\mathrm{S} 2$ and Additional file 1: Table S3) [10, 11]. Strains 3A12, 3C11 and 5C9 were identified as different isolates of Burkholderia gladioli, isolated from diverse Zea genotypes (Additional file 2: Table S4). Interestingly, using the in vitro dual culture screen, the same endophytes plus two additions $(3 \mathrm{H} 8,4 \mathrm{H} 12)$ were found to form inhibition zones of $S$. homoeocarpa growth on agar in all three replicates (Fig. 1g-i; Additional file 1: Table S3 and Additional file 2: Table S4). Strains $3 \mathrm{H} 8$ and $4 \mathrm{H} 12$ were identified as Bacillus subtilis and Paenibacillus polymyxa, respectively (Additional file 1: Table S3) [10, 11].

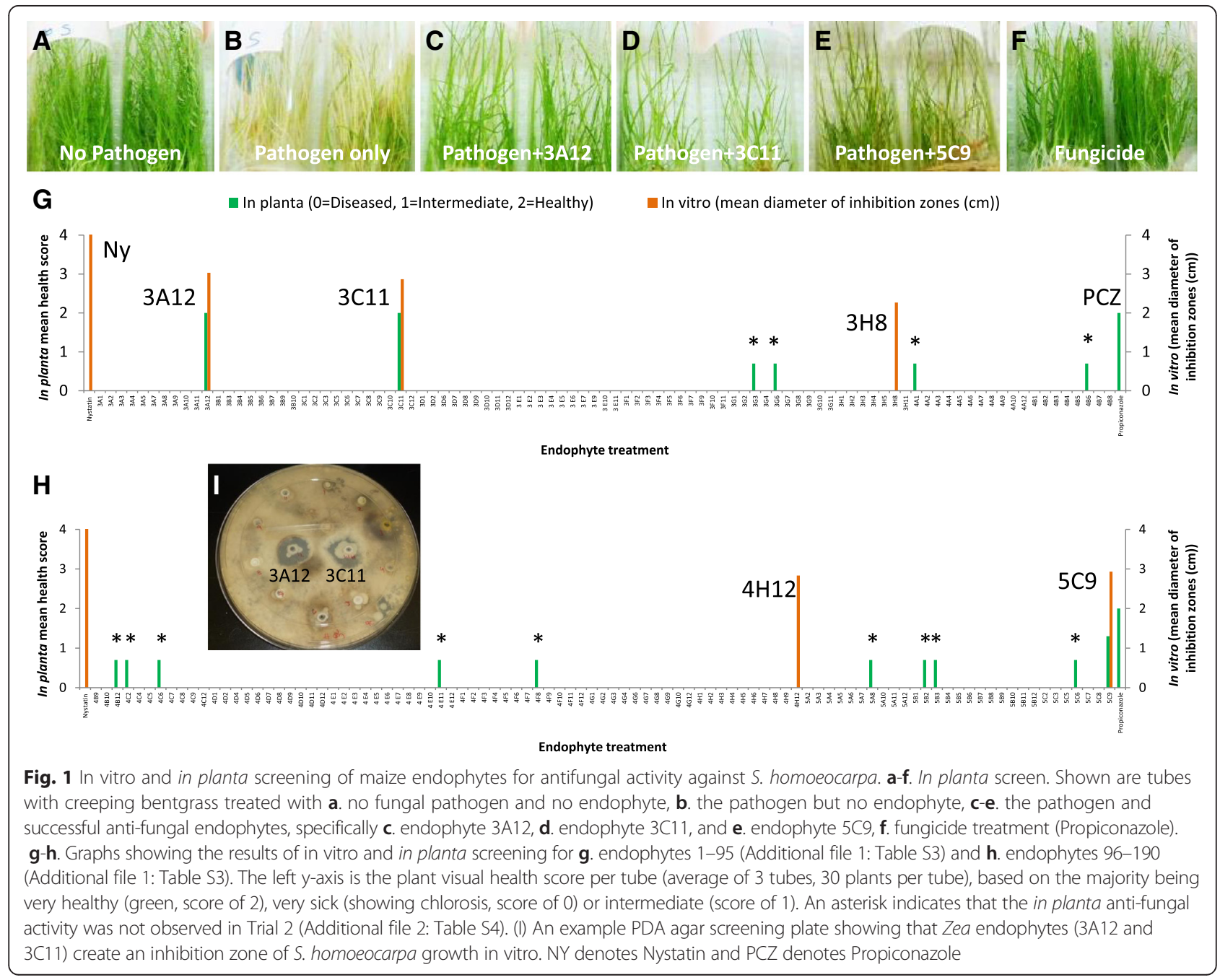




\section{Screening for inhibition of $R$. solani}

In planta, out of 190 endophytes screened, four endophytes (3A12, 3C11, 4H12, 5C9) controlled $R$. solani (Fig. 2a-f; Additional file 1: Table S3 and Additional file 2: Table S4) in all 3/3 tubes tested ( $n=\sim 30$ plants/tube). Using the in vitro dual culture screen, the same endophytes, plus one addition (3H8) suppressed $R$. solani growth in all three replicates (Fig. 2h-i; Additional file 1: Table S3 and Additional file 2: Table S4). The taxonomic identities of these strains are noted above.

\section{Discussion}

Parallel in vitro and in planta screens for anti-fungal activity have previously been reported, but with limited sample sizes. For example, amongst the largest parallel screens we could find, Aravind et al. [24] screened 74 endophytes from black pepper for activity against Phytophthora capsici. The authors identified 14 and 16-17 anti-fungal candidates based on in vitro and multiple in planta assays, respectively, but data was only presented for 12 strains that correlated [24]. Our study expands these results to 190 endophytes and two additional pathogens.

Here, all three out of 190 endophytes that showed consistent anti-fungal activity against $S$. homoeocarpa in planta, were captured in vitro (Fig. 3a). Similarly, all 4 endophytes that showed consistent activity against $R$. solani in planta were captured in vitro (Fig. 3b). However, the in vitro screen identified additional endophytes with anti-fungal activities that did not show activity in our in planta screen. Taking into account all 190 endophytes initially tested, the results from in vitro and in planta screening of endophytes that combat $S$. homoeocarpa positively correlated (Pearson $\mathrm{r}=$ 0.61, $p<0.0001$ ) (Additional file 1: Table S3). For the two anti- $R$. solani screens, the correlation was even greater (Pearson $\mathrm{r}=0.89, p<0.0001$ ) (Additional file 1: Table S3). Excluding the in planta results that could not be replicated (in these cases, only 1 out of 3 tubes initially showed some healthy plants), the correlations were stronger (Pearson $\mathrm{r}=0.80, p<0.0001$ for $S$. homoeocarpa; and $\mathrm{r}=0.91$, $p<0.0001$ for R. solani) (Additional file 2: Table S4).

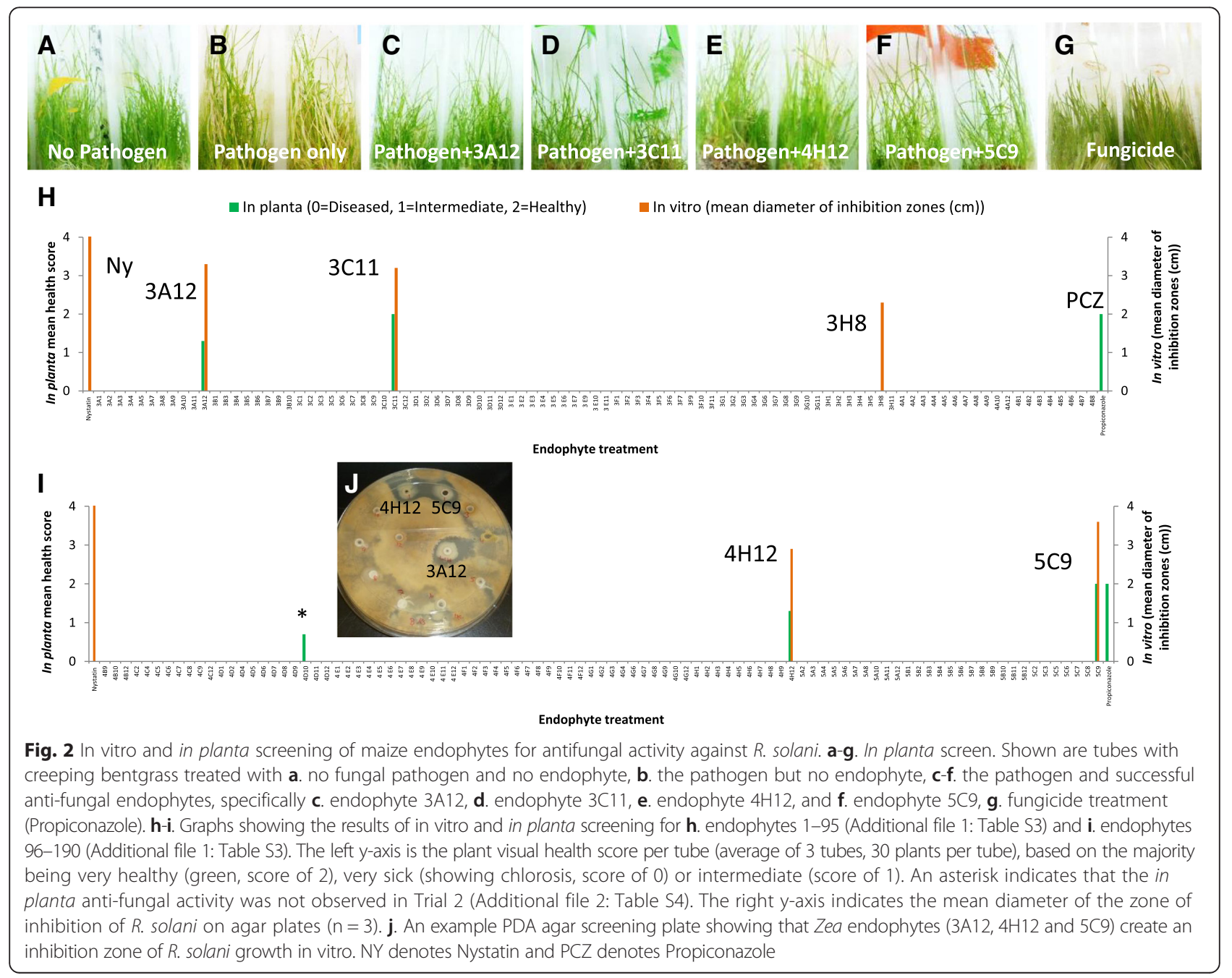



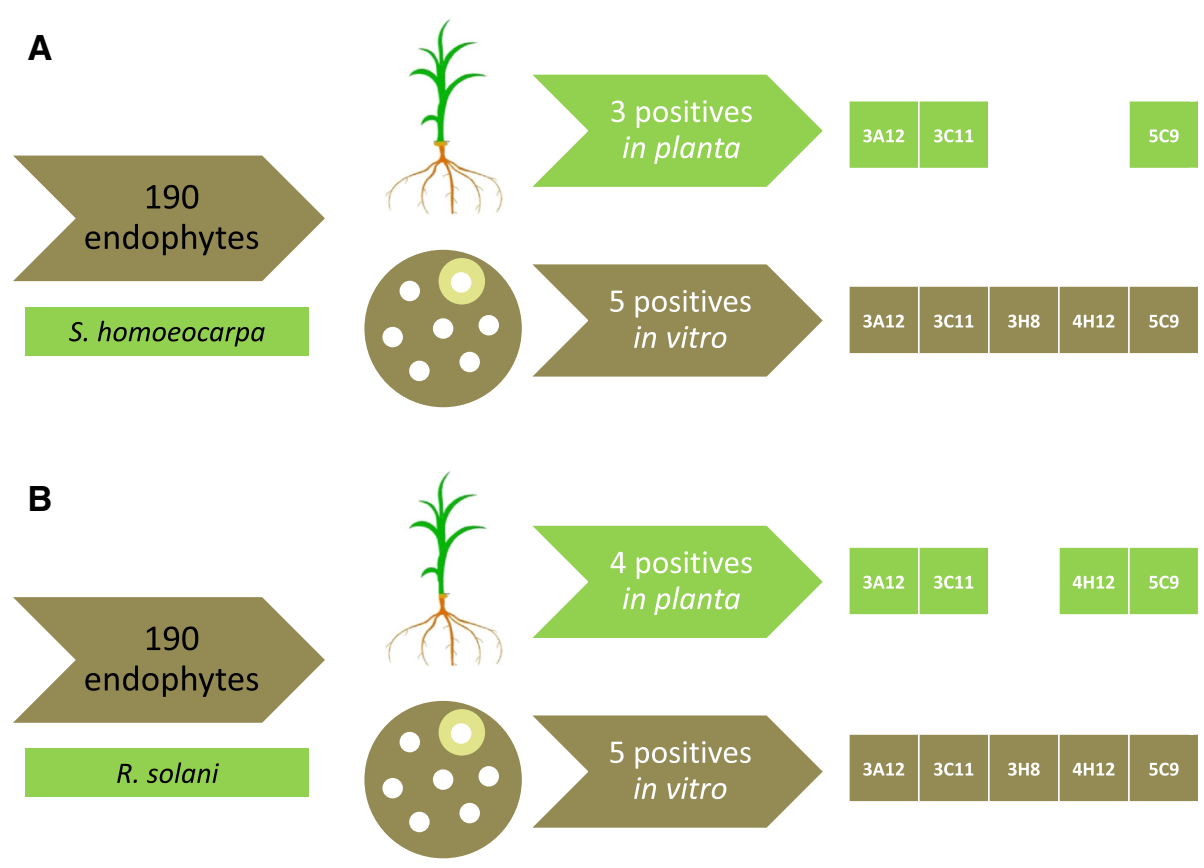

Fig. 3 A cartoon illustrating the correlation between the in vitro and in planta screens for Zea endophytes that showed antifungal activity against both S. homoeocarpa and R. solani

Our study shows that the in vitro screens captured all of the endophytes that showed anti-fungal activities in planta. These results may be interpreted in the context of the mechanisms by which endophytes control plant pathogens: induction of host resistance, direct antagonism, or competition $[25,26]$. The in vitro screen had the capacity to detect endophytes that combat pathogens mainly through direct antagonism and possibly through competition for agar nutrients, but the screen could not have captured endophytes that induce host resistance or compete for ecological plant niches [4, 27-29]. Therefore it is surprising that the in vitro assays captured all the candidates identified from the in planta screens. There may be at least two hypotheses to explain these results:

First, the above defense mechanisms are not mutually exclusive. It was previously reported that some antifungal compounds can also stimulate host resistance [25]. Hence it may be that induction of host resistance is taking place in some of the anti-fungal candidates but it is coupled with direct antagonism, allowing the endophyte (s) to be identified by in vitro screening. Second, the endophytes here were screened in a host different from their native host which may have affected their potential to induce host resistance or to compete with the fungal pathogen for space. Consistent with this hypothesis, in the above study by Aravind et al., the authors used the native endophyte host to screen for antifungal activity and reported that at least 3/17 and 2/17 anti-fungal endophytes identified using two in planta screens were not apparently identified in vitro [24]. Here we may have been able to capture additional endophytes with antifungal activity in planta by testing other plant species susceptible to the same pathogens. However, in another in planta screen using annual ryegrass (Lolium multiflorum) with endophytes \#1-75 (Additional file 1: Table S3), we have observed that the same two endophytes (3A12 and 3C11) suppress S. homoeocarpa (Additional file 4: Figure S1) as those that suppressed the pathogen in creeping bentgrass; these grasses belong to different genera. The third anti-fungal endophyte (5C9) also suppressed $S$. homoeocarpa in annual ryegrass (Additional file 1: Figure S1). In the future, it would be ideal to conduct parallel screens using the 14 native Zea hosts of these endophytes.

Our in vitro screens identified "false positives" with respect to the results in planta. This is consistent with previous studies. For example, Faltin et al. found that out of 17 plant associated microbes (including endophytes) that inhibited $R$. solani in vitro, 6 or 3 microbes, respectively, inhibited $R$. solani in lettuce leaf discs and in sugar beets [5]. In another study, 16/43 phylloplane and rhizosphere bacteria that inhibited Phytophthora infestans in vitro reduced disease symptoms by $>10 \%$ in planta in detached potato leaves with only two of these suppressing disease symptoms by $>75 \%$ [9]. Failure of some bacterial candidates from in vitro screens to suppress fungal disease when tested in planta may be attributed to many reasons, including: failure of endophytes to colonize the plant; 
failure of endophytes to migrate towards the pathogen; failure to compete with the native microbiota of their hosts; and/or sub-optimal production of anti-fungal compounds in planta due to pathways that compete for shared metabolic precursors, compared to optimized in vitro agar $[4,29]$. Alternatively, as our in planta screen was visual, it may have missed endophytes that had only weak antifungal activities.

\section{Conclusions}

There are practical and biological advantages and disadvantages to both in vitro and in planta screens for microbes with anti-fungal activity [29]. Nevertheless, our results and previous reports suggest that in vitro dual culture screening is a good method for high-throughput characterization of endophyte communities for antifungal activity, generally capturing the microbes that display these activities in planta.

\section{Methods \\ Biological materials}

Bacterial endophytes were isolated from seeds, roots and shoots of 14 different genotypes of Zea (Additional file 5 : Table S1, Additional file 3: Table S2 and Additional file 1: Table S3) as previously reported [10, 11]. Sclerotinia homoeocarpa and Rhizoctonia solani were obtained from the Guelph Turfgrass Institute, Guelph, Canada. Creeping bentgrass (CB, Agrostis stolonifera, PENN A-4) seeds were obtained from the Ontario Seed Company, Kitchener, Canada. Annual ryegrass (AR, Lolium multiflorum L., Annuity) seeds were obtained from Seed Research of Oregon, USA.

\section{In planta screen}

\section{Preparation of endophyte coating agent mixture}

Endophytes were cultured in LB overnight at $37{ }^{\circ} \mathrm{C}$, shaking at $250 \mathrm{rpm}$. Cells were centrifuged, washed twice in $10 \mathrm{mM}$ tris $\mathrm{HCl}(\mathrm{pH} 7)$, then suspended to $\mathrm{OD}_{595}=0.5$. From each suspension, $500 \mu \mathrm{l}$ were diluted in $5 \mathrm{ml}$ of $9.3 \%$ PVP aqueous solution (P-5288, Sigma, USA) and used to coat creeping bentgrass seeds.

\section{Coating of seeds}

$\mathrm{CB}$ seeds were surface sterilized by washing with $70 \%$ ethanol for $1 \mathrm{~min}$, bleach for $20 \mathrm{~min}$, then rinsed 6 times with water. $100 \mathrm{CB}$ seeds were added to each endophytePVP mixture $(5 \mathrm{ml})$ and coated for $1 \mathrm{~h}$ on a rotary shaker.

\section{Growing Turfgrass}

Modified MS medium was used to germinate and grow $\mathrm{CB}$, consisting of (per L, pH 5.8): half-strength modified basal salt MS (M571, Phytotech, USA), $250 \mu$ l nicotinic acid $(1 \mathrm{mg} / \mathrm{ml}), 500 \mu \mathrm{l}$ pyridoxine $\mathrm{HCl}(0.5 \mathrm{mg} / \mathrm{ml}), 5 \mathrm{ml}$ thiamine $\mathrm{HCl}(100 \mathrm{mg} / \mathrm{l}), 500 \mu \mathrm{l}$ glycine $(2 \mathrm{mg} / \mathrm{ml}), 2 \mathrm{~g}$
Phytagel (P8169, Sigma, USA) in $\mathrm{ddH}_{2} 0$. To solidify Phytagel, $0.166 \mathrm{~g} / \mathrm{l} \mathrm{CaCl}_{2}$ and $90 \mathrm{mg} / \mathrm{l} \mathrm{MgSO}_{4}$ were added. Sterile MS (15 ml) was aliquoted into sterile $15 \mathrm{~cm} \times 25 \mathrm{~mm}$ covered glass tubes (C5916, C5791, Sigma, USA). Per tube, 30 endophyte-coated CB seeds were placed on the media surface, in triplicate, allowed to germinate for $7 \mathrm{~d}$ in darkness, moved to a growth chamber (BTC-60, Enconair, Winnipeg, Canada) and grown under the following conditions: $25{ }^{\circ} \mathrm{C}$ constant, $16 \mathrm{~h}$ cool white fluorescent light (Philips F72T8/TL841/HO $65 \mathrm{~W}, 115-145 \mu \mathrm{mol} \mathrm{m}{ }^{-2} \mathrm{~s}^{-1}$ measured using a Quantum BMQ Meter, Apogee Instruments, Logan, UT, USA).

\section{Inoculation with pathogens}

$S$. homoeocarpa and $R$. solani were grown on Potato Dextrose Agar (PDA) for $5 \mathrm{~d}$ at $28{ }^{\circ} \mathrm{C}$. Discs from these plates were used to inoculate $\mathrm{CB}$ tubes after $10 \mathrm{~d}$ of plant growth. Controls were seeds coated with PVP but without endophytes, plus/minus each pathogen. For the fungicide treatment, Banner Maxx (Propiconazole 14.3 \%, 60207 90-1, Syngenta Crop Protection, Canada) was used at a rate of $51 \mathrm{ml}$ per $100 \mathrm{~m}^{2}$, applied as a spray 1 week after germination.

\section{Re-inoculation of turfgrass}

Two weeks after seed coating, glass tubes were reinoculated with $100 \mu \mathrm{l}$ of each endophyte cell suspension $\left(\mathrm{OD}_{595}=0.5\right.$ in $10 \mathrm{mM}$ tris $\mathrm{HCl}, \mathrm{pH}$ 7). For control plants, $100 \mu \mathrm{l}$ of $10 \mathrm{mM}$ tris $\mathrm{HCl}(\mathrm{pH} 7)$ were used.

\section{Assessing disease symptoms in planta}

Four weeks after germination, plants were assessed using a visual rating scale, based on the majority being very healthy (green, score of 2), very sick (showing chlorosis, score of 0 ) or intermediate (score of 1). Endophytes that showed anti-fungal activity were re-tested in an independent trial.

\section{Testing candidate endophytes against S. homoeocarpa in annual ryegrass (L. multiflorum)}

Annual ryegrass (AR) was used as another grass host to test the candidate antifungal endophytes against S. homoeocarpa. The same protocol for in planta screen was used with two modifications: 30 AR seeds were added to each endophyte-PVP mixture, and only 7 seeds were used per tube.

\section{In vitro screen}

Dual culture screens were used. S. homoeocarpa and $R$. solani were cultured in YPD media at $25^{\circ} \mathrm{C}, 80 \mathrm{rpm}$ for 3 d. PDA was cooled to $50{ }^{\circ} \mathrm{C}$, mixed with each fungal culture $(1: 25 \mathrm{v} / \mathrm{v})$, then poured into Petri plates $(150 \mathrm{~mm} \times$ $15 \mathrm{~mm})$. Holes were created in the agar using Pasteur pipettes; plugs were removed using a sterilized wire loop. In 
parallel, endophytes were cultured overnight in LB at $37^{\circ} \mathrm{C}$ at $250 \mathrm{rpm}$, then $\mathrm{OD}_{595}$ adjusted to 0.4 to 0.6 . Fifty microlitres of each culture were applied to the fungal plates in triplicate, incubated at $25^{\circ} \mathrm{C}$ for $3-5 \mathrm{~d}$, and then zones of inhibition of fungi were measured. Endophytes showing anti-fungal activity were re-tested in an independent trial. Nystatin (N581, PhytoTechnology Laboratories, USA) was used as a control fungicide at a concentration of 303 units/well.

\section{Statistical analysis}

GraphPad Prism 6 was used for Pearson correlation analysis.

\section{Research involving plants}

This study was conducted using local, commercially available plant seed, with plants grown entirely indoors followed by autoclaving. The study conforms to all Canadian guidelines, and does not require any special permissions or licenses.

\section{Availability of data and materials}

The 16S rRNA sequences of endophytes used in this study have been deposited into Genbank (Additional file 3: Table S2). The authors agree to make available all microbial strains to non profit, public sector institutions.

\section{Additional files}

Additional file 1: Table S3. List of all Zea endophytes used in this study and anti-fungal screening results. (XLSX $26 \mathrm{~kb}$ )

Additional file 2: Table S4. In planta re-testing of Zea endophytes that showed anti-fungal activity in planta in Trial 1. (XLSX $18 \mathrm{~kb}$ )

Additional file 3: Table S2. Genebank accession numbers for 165 rRNA sequences of Zea endophytes used in this study. (DOCX $18 \mathrm{~kb}$ )

Additional file 4: Figure S1. In planta screening of maize endophytes for antifungal activity against S. homoeocarpa in annual ryegrass. Shown are tubes with annual ryegrass treated with $(A)$ no fungal pathogen and no endophyte, (B) the pathogen but no endophyte, (C-E) the pathogen and successful anti-fungal endophytes, specifically (C) endophyte $3 \mathrm{~A} 12$, (D) endophyte 3C11, and (E) endophyte 5C9, (F) fungicide treatment (Propiconazole). (PDF 198 kb)

Additional file 5: Table S1. The origins of the Zea genotypes used to isolate the endophytes noted in this study. (DOCX $16 \mathrm{~kb}$ )

\section{Abbreviations}

AR: annual ryegrass; CB: creeping bentgrass; PDA: potato dextrose agar; PVP: polyvinylpyrrolidone; YPD: yeast extract peptone dextrose.

\section{Competing interests}

The authors declare that they have no competing interests.

\section{Authors' contributions}

HRS helped to design the study, carried out all experiments, performed the analyses, and wrote the manuscript. KSJ and EML helped to design the study and generated materials. MNR helped to design the study and edited the manuscript. All authors read and approved the final manuscript.

\section{Acknowledgements}

We thank undergraduate students, Marina Atalla and Navneet Madhar, for technical help. HRS was supported by a generous scholarship from the Egyptian Government. This research was supported by grants to MNR from the Ontario Turfgrass Research Foundation and the Growing Forward 2 program of the Agricultural Adaptation Council and Agriculture and Agri-Food Canada.

\section{Author details}

${ }^{1}$ Department of Plant Agriculture, University of Guelph, Guelph, ON N1G 2W1, Canada. ${ }^{2}$ Department of Microbiology, School of Pharmacy, Mansoura University, Mansoura, Egypt.

Received: 28 August 2015 Accepted: 8 January 2016

Published online: 16 January 2016

\section{References}

1. Wani Z, Ashraf N, Mohiuddin T, Riyaz-Ul-Hassan S. Plant-endophyte symbiosis, an ecological perspective. Appl Microbiol Biot. 2015;99(7):2955-65. doi:10.1007/ s00253-015-6487-3.

2. Reinhold-Hurek $B$, Hurek T. Living inside plants: bacterial endophytes. Curr Opin Plant Biol. 2011;14(4):435-43. http://dx.doi.org/10.1016/j.pbi.2011.04.004

3. Rey T, Schornack S. Interactions of beneficial and detrimental rootcolonizing filamentous microbes with plant hosts. Genome Biol. 2013;14(6): 121. doi:10.1186/gb-2013-14-6-121.

4. Pliego C, Ramos C, Vicente A, Cazorla F. Screening for candidate bacterial biocontrol agents against soilborne fungal plant pathogens. Plant Soil. 2011; 340(1-2):505-20. doi:10.1007/S21104-010-0615-8.

5. Faltin F, Lottmann J, Grosch R, Berg G. Strategy to select and assess antagonistic bacteria for biological control of Rhizoctonia solani Kühn. Can J Microbiol. 2004:50(10):811-20. doi:10.1139/w04-063.

6. Kheirandish Z, Harighi B. Evaluation of bacterial antagonists of Ralstonia solanacearum, causal agent of bacterial wilt of potato. Biol Control. 2015; 86(1):14-9. http://dx.doi.org/10.1016/j.biocontrol.2015.03.007.

7. Yang L, Quan X, Xue B, Goodwin PH, Lu S, Wang J, et al. Isolation and identification of Bacillus subtilis strain YB-05 and its antifungal substances showing antagonism against Gaeumannomyces graminis var. tritici. Biol Control. 2015;85(1):52-8. doi:10.1016/j.biocontrol.2014.12.010.

8. Khabbaz SE, Zhang L, Cáceres LA, Sumarah M, Wang A, Abbasi PA. Characterisation of antagonistic Bacillus and Pseudomonas strains for biocontrol potential and suppression of damping-off and root rot diseases. Ann Appl Biol. 2015;166(3):456-71. doi:10.1111/aab.12196

9. Daayf F, Adam L, Fernando WGD. Comparative screening of bacteria for biological control of potato late blight (strain US-8), using in vitro, detached-leaves, and whole-plant testing systems. Can J Plant Pathol. 2003; 25(3):276-84. doi:10.1080/07060660309507080.

10. Johnston-Monje D, Mousa W, Lazarovits G, Raizada MN. Impact of swapping soils on the endophytic bacterial communities of pre-domesticated, ancient and modern maize. BMC Plant Biol. 2014;14:233. doi:10.1186/S22870-014-0233-3.

11. Johnston-Monje D, Raizada MN. Conservation and diversity of seed associated endophytes in Zea across boundaries of evolution, ethnography and ecology. PLoS One. 2011;6(6), e20396. doi:10.1371/journal.pone.0020396.

12. Casler MD. Perennial grasses for turf, sport and amenity uses: evolution of form, function and fitness for human benefit. J Agri Sci. 2006;144(3):189-203. doi:10.1017/s0021859606006137

13. Rioux RA, Shultz J, Garcia M, Willis DK, Casler M, Bonos S, et al. Sclerotinia homoeocarpa overwinters in turfgrass and is present in commercial seed. PLoS One. 2014;9(10), e110897. doi:10.1371/journal.pone.0110897.

14. Daniels JP, Latin R. Residual efficacy of fungicides for controlling brown patch on creeping bentgrass fairways. Plant Dis. 2013;97(12):1620-5. doi:10. 1094/pdis-12-12-1130-re.

15. Beirn LA, Tredway L, Boehm M, Orshinsky A, Putman A, Carbone I, et al. A new name for an age-old fungus: unraveling the mystery of dollar spot disease of turfgrass. Phytopathol. 2013;103(6):14.

16. Walsh B, Ikeda SS, Boland GJ. Biology and management of dollar spot (Sclerotinia homoeocarpa); an important disease of turfgrass. HortSci. 1999;34(1):13-21.

17. Jeon S, Naing K, Lee Y, Nguyen X, Kim S, Kim K. Promotion of growth and biocontrol of brown patch disease by inoculation of Paenibacillus ehimensis KWN38 in bentgrass. Hortic Environ Biotechnol. 2015;56(2):263-71. doi:10. 1007/S23580-015-0109-y. 
18. Tsror L. Biology, epidemiology and management of Rhizoctonia solani on Potato. J Phytopathol. 2010;158(10):649-58. doi:10.1111/j.1439-0434.2010.01671.x.

19. Kataria HR, Wilmsmeier B, Buchenauer H. Efficacy of Pseudomonas fluorescens strains and some modern fungicides for control of Rhizoctonia solani AG-4 in bean and cucumber. J Plant Dis Protect. 2002;109(4):384-400.

20. Pascual CB, Raymundo AD, Hyakumachi M. Suppression of Rhizoctonia solani in corn by hypovirulent binucleate Rhizoctonia and the nature of protection. Philipp Agric Sci. 2004;87(1):36-40.

21. Akhter W, Bhuiyan MKA, Sultana F, Hossain MM. Integrated effect of microbial antagonist, organic amendment and fungicide in controlling seedling mortality (Rhizoctonia solani) and improving yield in pea (Pisum sativum L.). C R Biol. 2015;338(1):21-8. doi:10.1016/j.crvi.2014.10.003.

22. Montealegre JR, Reyes R, Perez LM, Herrera R, Silva P, Besoain X. Selection of bioantagonistic bacteria to be used in biological control of Rhizoctonia solani in tomato. Electron J Biotechnol. 2003:6(2):115-27.

23. Chen B, Li LW, Lin YJ, Wang ZH, Lu GD. Evaluation of seedling resistance of rice germplasm resources to sheath blight (Rhizoctonia solani). Cereal Res Commun. 2014;42(3):495-502. doi:10.1556/crc.42.2014.3.12.

24. Aravind R, Kumar A, Eapen SJ, Ramana KV. Endophytic bacterial flora in root and stem tissues of black pepper (Piper nigrum L.) genotype: isolation, identification and evaluation against Phytophthora capsici. Lett Appl Microbiol. 2009;48(1):58-64. doi:10.1111/j.1472-765X.2008.02486.X.

25. Lugtenberg B, Kamilova F. Plant-growth-promoting rhizobacteria. Annu Rev Microbiol. 2009;63:541-56. doi:10.1146/annurev.micro.62.081307.162918.

26. Rosenblueth M, Martínez-Romero E. Bacterial endophytes and their interactions with hosts. Mol Plant-Microbe Interact. 2006;19(8):827-37. doi: 10.1094/mpmi-19-0827.

27. Kamilova F, Validov S, Azarova T, Mulders I, Lugtenberg B. Enrichment for enhanced competitive plant root tip colonizers selects for a new class of biocontrol bacteria. Environ Microbiol. 2005;7(11):1809-17. doi:10.1111/j. 1462-2920.2005.00889.x.

28. Pang Y, Liu X, Ma Y, Chernin L, Berg G, Gao K. Induction of systemic resistance, root colonisation and biocontrol activities of the rhizospheric strain of Serratia plymuthica are dependent on $\mathrm{N}$-acyl homoserine lactones. Eur J Plant Pathol. 2009;124(2):261-8. doi:10.1007/S20658-008-9411-1.

29. Knudsen IMB, Hockenhull J, Jensen DF, Gerhardson B, Hökeberg M, Tahvonen $\mathrm{R}$, et al. Selection of biological control agents for controlling soil and seed-borne diseases in the field. Eur J Plant Pathol. 1997;103(9):775-84. doi:10.1023/a:1008662313042.

\section{Submit your next manuscript to BioMed Central and we will help you at every step:}

- We accept pre-submission inquiries

- Our selector tool helps you to find the most relevant journal

- We provide round the clock customer support

- Convenient online submission

- Thorough peer review

- Inclusion in PubMed and all major indexing services

- Maximum visibility for your research

Submit your manuscript at www.biomedcentral.com/submit

C Biomed Central 